\title{
Ethnobotany genomics research: Status and future prospects
}

\author{
Franky Varah*, Pranav N. Desai \\ Centre for Studies in Science Policy, School of Social Sciences, Jawaharlal Nehru University, New Delhi, India
}

\begin{abstract}
The present study is an attempt to analyze the world publication of ethnobotany genomics by using "DNA barcoding" and "DNA barcoding plants" as keywords. Some of the parameters used for the analysis include the publication output, countries' performance, the institutions involved, subject areas, authors, and journals distribution. The Scopus International Database is used for this purpose. An evaluating indicator, citations and h-index are applied to characterize the ethnobotany genomic publication output. It is interesting to note that over the past decade, there has been a notable growth in publication output. Moreover, there has been a significant increase in the participation from a number of countries as well as institutions, subject categories, journals, authors, and collaborations. The increasing significance of ethnobotany genomics was analyzed by ranking countries, institutions, subject categories, journals, authors and collaborations in terms the total number of publication, their citations and h-index.
\end{abstract}

Keywords: DNA barcoding, ethnobotany genomics, h-index and citation, productivity, publication, scientometric

\section{INTRODUCTION}

In recent times, ethnobotanical (the aim of ethnobotany is to study how and why people use and conceptualize plants in their local environments. The discipline addresses how and in what ways people use and view nature. As a field of research and study, ethnobotany is an interdisciplinary, holistic approach that includes botany, anthropology, history, chemistry etc.) research has gained a vital role for the discovery of new drugs and new drug development (Bannister and Barrets 2001; Cotton, 1996). ${ }^{[1,2]}$ The important role of ethnobotany is enhanced by the fact that it has the potentiality of providing historical evidence

*Address for correspondence:

E-mail: akyvarah@gmail.com

\begin{tabular}{|l|l|}
\hline \multicolumn{2}{|c|}{ Access this article online } \\
\hline Quick Response Code: & \\
\hline & Website: \\
\hline & www.jscires.org \\
& \\
\hline
\end{tabular}

about medicinal uses of certain plants, which addresses the concerns over efficacy, safety aspects, and identification of species in the usage of modern botanicals. At the same time, in many cases, over-harvesting, degradation of medicinal plants, and losses of traditional medical knowledge in local communities are common problems in the world (Balick and Cox 1996; Sheng-Ji, 2001). ${ }^{[3,4]}$ Therefore, modern technology like genomics (the term "genomics" was coined by mouse geneticist Tom Roderick to describe an approach to the study of DNA at the level of chromosomes, entire genomes, or large clusters of genes) has emerged as a vital tool for the researchers engaged in biodiversity, and who deal with the inventory and management of earth's immense and changing biodiversity. Identification at the species level is required for quality assurance, which includes both identifying the crude plant product and evaluating its pharmaceutical quality (Wagner et al. 2011). ${ }^{[5]}$ Genomics have become a powerful tool for identification and authentication of biodiversity species (Kaplan et al. 2004; Pereira et al. 2008). ${ }^{[6,7]}$

Today, DNA barcoding (genomics) has principally emerged as an area that provides a forum for the exchange of information in the fields of biological studies. It serves as a rapid and cost-effective method for the identification of biodiversity, and 
is revolutionizing the application of taxonomy for taxa with validated data sets (Herbert et al. 2003; Becker et al. 2011). . $^{[8,9]}$ In this way, DNA barcoding could also improve large surveys aimed at unknown species detection, and identification of pathogenic species with medical, ecological, and agronomical significance (Armstrong and Ball, 2005). ${ }^{[10]}$ Furthermore, it has turned out to be a valuable asset in identifying of species, where morphological identification was not possible earlier, particularly in cryptic, microscopic and other organisms with complex or inaccessible morphology (Herbert et al., 2003). ${ }^{[8]}$ Thus, a wide range applications of DNA barcoding are emerging in the field of biodiversity conservation that ensures bio-security, protection of species, and is instrumental in avoiding pandemics (Ball and Armstrong, 2006; Frézal and Raphael, 2008). ${ }^{[11,12]}$

The emerging field of "ethnobotany genomics" (Ragupathy et al. 2009; Newmaster and Ragupathy, 2010), ${ }^{[13,14]}$ or "phylogenetic ethnobotany" (Ronsted et al. 2008, 2012; Saslis-Lagoudakis et al. 2011) ${ }^{[15,16,17]}$ involves and allows the combination of traditional knowledge and genomic information. This has pushed the field of ethnobotany to embrace genomic tools and use genetic identification to distinguish plant material, or to differentiate between several species that are possibly derived from a common name (Ragupathy et al. 2009; Newmaster and Ragupathy, 2010; Maloles et al. 2011). ${ }^{[13,14,18]}$

Steven Newmaster and his colleagues present the use of DNA barcoding in a new approach to ethnobotany termed as "ethnobotany genomics." This concept is built around the idea of "assemblage" of diverse knowledge of biodiversity that includes a coming together of the different ways of knowing and valorizing species variation. It involves a novel approach that seeks to add value to both traditional knowledge and scientific knowledge (Ragupathy et al. 2009; Newmaster and Ragupathy 2010). ${ }^{[13,14]}$ Ethnobotany genomics draws on the body of ancient knowledge concerning the variation in the biodiversity that surrounds different culture. It then combines this knowledge with modern genomic tools such as DNA barcoding to explore the natural genetic variation found among organism. As a result, ethnobotany genomics have proved to be an extremely versatile and valuable tool that has found application in various fields. Consequently as they work together to create innovative knowledge, potentially in biodiversity conservation strategies, a study in this direction adds value to both traditional knowledge and scientific knowledge based approaches in our understanding of diversity. This may also help in understanding and protecting both the cultural and biological diversity, as urged by the Convention of Biological Diversity, United Nations Educational, Scientific and Cultural Organization and the Declaration on the Rights of Indigenous People (Ragupathy et al. 2009; Newmaster and Ragupathy, 2010). ${ }^{[13,14]}$

DNA barcoding was proposed in 2003 as a tool for species identification for short gene sequencing from a standardized region of the genome (Hebert et al. 2003).$^{[8]}$ Now, this method has gained popularity and become a well-funded global enterprise for identification, delimitation and discovery. Thus, it follows that publications on ethnobotany genomics research registered an expeditious increase in the quantity over the past decades, and a number of papers documenting on the latest research achievements have been published in reputed scientific journals. However, despite the high growth rate of ethnobotany genomics publications, so far no attempts have been made for deploying scientometric methods to systematically study the global scientific production of ethnobotany genomics research.

\section{Objectives}

The main objective of this study was to look into the world research output in ethnobotany genomics. In particular, the study focuses on the flowing objectives:

- To study the world research output, its growth, rank and publications of top countries and institutions

- To identify the publications output of leading subject categories, journals, collaborations and authors

- To analyze the quality and significance of publications using citation and h-index.

\section{METHODOLOGY}

The bibliographic data on ethnobotany genomics research carried out in the world have been collected from Scopus International Database for the publication. First, the term "DNA barcoding" has been coined in 2003, hence the keyword "DNA barcoding" is used in the title, abstract and keywords field to collect publication data pertaining to genomics from the year 2003 to July 2013 which includes all biodiversity. However, "DNA barcoding plants" which is an only limited to plants came into existence from the year 2005, which is why the keyword "ethnobotany genomics, DNA barcoding plants" is used in the title, abstract, and keywords field to collect publication data pertaining to ethnobotany genomics in the year 2005-2014. 
To analyze the significance of countries, institutions, subject categories, journals, collaborations and authors, separate search strategies were developed and combined with the main string to generate the desired output. However, all these may indicate the voluminous production and not necessarily indicate the development trends in the field of research. The articles represented the majority of document types that were identified, and the rest were discarded. Further, an attempt has been made to employ the citation data and h-index. Similarly, in the citation data and h-index to extract data, separate search strategies were developed, and later combined with the main string to evaluate the research productivity. Finally, after removal of irrelevant information manually, the data set of publications was retrieved and analyzed using MS-Excel as per the objectives of the study.

\section{ANALYSES AND INTERPRETATION}

\section{Year Wise Distribution of Publications Output}

Table 1 shows the number of citations that an article has received, and the average citations per article, respectively. Cumulative article shows the growth trend in the number of articles. During, the period 2003-2013, the world's cumulative publication output in genomics research consisted of 2128 articles, with an average number of 193.4 articles published per year. During this period, the cumulative number of articles grew from one article in 2003 to 550 articles in 2012. The cumulative world publications output in genomics research increased from 171 articles during 2003-2007 to 1957 articles during 2008-2013, testifying that the research had aroused more and more concern all over the world. Further, in terms of impact and citation quality, the average citation per article registered by world publication output in genomics was 16.18 during 2003-2013 [Table 1].

Table 2 reveals that during the period of 2005-2014, a total of 710 publications were published in ethnobotany genomics in the world. The highest number of publication was 142 in 2012. From the period 2005-2009 to 2010-2014 the number of publications is 106 and 604 respectively, which shows a rapid rise in the number of publications in ethnobotany genomics [Table 2].

\section{Publication Performances of Selected Countries}

There are a total of 112 countries taking part in the genomics research in the world. Table 3 shows that during the period 2003-2013, the top 20 most productive countries in genomics research varied from 42 to 636 total articles [Table 2], in which USA tops the list, followed by Canada, UK and so on. A comparison of the growth trends of the Brazil, Russia, India, China, and South Africa (BRICS) countries is displayed in Figure 1. BRICS had the fastest growing economies in the world. The

\begin{tabular}{|c|c|c|c|c|}
\hline Year & TA & Cumulative article & TC & ACPA \\
\hline 2003 & 1 & 1 & 919 & 919 \\
\hline 2004 & 7 & 8 & 1398 & 199.71 \\
\hline 2005 & 32 & 40 & 4239 & 132.46 \\
\hline 2006 & 44 & 84 & 3034 & 68.95 \\
\hline 2007 & 87 & 171 & 4916 & 56.50 \\
\hline 2008 & 127 & 298 & 4781 & 37.64 \\
\hline 2009 & 230 & 528 & 5798 & 25.20 \\
\hline 2010 & 334 & 862 & 4871 & 14.58 \\
\hline 2011 & 417 & 1279 & 2955 & 7.08 \\
\hline 2012 & 550 & 1829 & 1454 & 2.64 \\
\hline 2013 & 299 & 2128 & 75 & 0.25 \\
\hline 2003-07 & 171 & & 14,506 & 84.83 \\
\hline $2008-12$ & 1658 & & 19,859 & 11.97 \\
\hline $2003-13$ & 2128 & & 34,440 & 16.18 \\
\hline
\end{tabular}

$\mathrm{TA}=$ Total articles, $\mathrm{TC}=$ Total citations, $\mathrm{ACPP}=$ Average citations per article

Table 2: Year wise distribution of ethnobotany genomics publications output

\begin{tabular}{lcccc}
\hline Year & TA & Cumulative article & TC & ACPA \\
\hline 2005 & 3 & 3 & 12 & 4 \\
2006 & 9 & 12 & 33 & 3.67 \\
2007 & 8 & 20 & 67 & 8.37 \\
2008 & 27 & 47 & 120 & 4.45 \\
2009 & 59 & 106 & 264 & 4.47 \\
2010 & 84 & 190 & 477 & 5.67 \\
2011 & 114 & 304 & 780 & 6.84 \\
2012 & 143 & 447 & 905 & 6.32 \\
2013 & 135 & 582 & 798 & 5.91 \\
2014 & 128 & 710 & 696 & 5.43 \\
$2005-2009$ & 106 & & 973 & 9.18 \\
$2010-2014$ & 604 & & 3656 & 6.05 \\
$2005-2014$ & 710 & & 4152 & 5.84 \\
\hline TA & & &
\end{tabular}

$\mathrm{TA}=$ Total articles, $\mathrm{TC}=$ Total citations, $\mathrm{ACPP}=$ Average citations per article

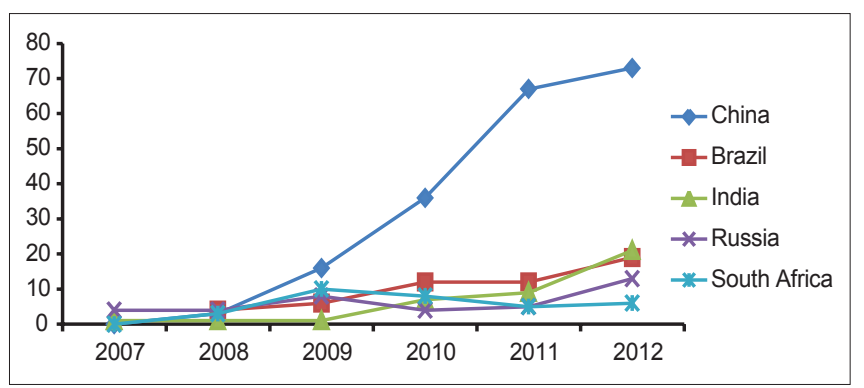

Figure 1: The trends of the Brazil, Russia, India, China, and South Africa countries in genomic research 
publications from China grew sharply, while those of Brazil, Indian and Russia, except South Africa, increased gradually during the period from 2008 to 2012, which might be evidence of the remarkable differences in the development of their respective technologies. For instance, only three articles from China were published in 2008, but by 2012 , the number has increased sharply to 73 . China had a higher growth rate than others and was rapidly close with the top country that is, USA. There is no doubt that a series of positive policies had motivated the rapid development of research in China.

The quality of articles published by these productive countries in terms of average citation per article varies from 3. 67 to 32.49 during 2003-2013. The highest citation impact is registered by Canada with 32.49 citations per article, followed by Denmark (25) USA (23.49) and others [Table 3]. Measuring the performance of these countries on the basis of $h$-index, the seven top countries in the number of articles publication, have achieved a higher h-index value than the group average of 20.55, excluding of China (20).

Table 3 shows that USA dominated the rankings both in terms of the total number of articles and h-index, and had the $3^{\text {rd }}$ highest average citations per article of 23.49. However, on an average citation per article Canada was ranked first among the top 20 countries (32.48). While Denmark was ranked $19^{\text {th }}$ in the number of article publication, it occupies the second position in terms of average citations per article (25.04). It is notable that despite China being ranked $4^{\text {th }}$ in terms of the number of article publications, it is ranked $19^{\text {th }}$ in terms of average citations per article, and less than the group average in terms of h-index.

On the other hand, at present, there are 72 countries participating in the ethnobotany genomics research. Table 4 represents the publication of the top ten most productive countries in ethnobotany genomics, which varies from 31 to 171 during 2005-2014. Here also the USA tops the list with 171, followed by China (158), Canada (78), UK (75), France (60), India (43) followed by others. From Table 4, it is evident that China and India are rapidly emerging in their publications. In terms of average citation per article, the highest (35.21) is achieved by UK, followed by Canada (24.17), France (19.55), USA (18.42), followed by others [Table 4]. On the other hand, developing countries including China and India have shown an increase in their publications share in ethnobotany genomics. For China, the number of articles grew from six in 2005-2009 to 152 in 2010-2014, and for India from two articles in 2005-2009 to 41 in 2010-2014.

Tables 3 and 4 show that USA, Canada, and UK were dominating the rankings in terms of the total number of articles, h-index, and average citations per article. But it does not come as a surprise that these countries produce more numbers and quality publications because a majority of the international research organizations and initiatives related to ethnobotany genomics were in these countries.

\begin{tabular}{lcccc}
$\begin{array}{l}\text { Table 3: The top } \\
\text { research }\end{array}$ & \multicolumn{4}{l}{ productive countries in genomics } \\
\hline Country & TA & TC & ACPA & h-index \\
\hline USA & 636 & 14,940 & 23.49 & 59 \\
Canada & 380 & 12,346 & 32.48 & 53 \\
UK & 254 & 4865 & 19.15 & 34 \\
China & 227 & 1537 & 6.77 & 20 \\
Germany & 224 & 3935 & 17.56 & 29 \\
France & 179 & 2806 & 15.67 & 28 \\
Australia & 126 & 2227 & 17.67 & 22 \\
Italy & 94 & 1026 & 10.91 & 15 \\
The Netherlands & 76 & 1452 & 19.10 & 18 \\
Spain & 71 & 759 & 10.69 & 16 \\
Brazil & 66 & 704 & 10.66 & 12 \\
Japan & 66 & 451 & 6.83 & 12 \\
New Zealand & 55 & 886 & 16.10 & 13 \\
India & 53 & 195 & 3.67 & 6 \\
Sweden & 52 & 978 & 18.80 & 14 \\
Belgium & 49 & 481 & 9.81 & 13 \\
Mexico & 48 & 663 & 13.81 & 9 \\
South Korea & 45 & 686 & 15.24 & 12 \\
Denmark & 42 & 1052 & 25.04 & 13 \\
Russia & 42 & 413 & 9.83 & 13 \\
\hline TA=Total articles, TC $=$ Total citations, ACPP $=$ Average citations per article
\end{tabular}

Table 4: The top 10 productive countries in ethnobotany genomics research

\begin{tabular}{lccccc}
\hline Country & \multicolumn{3}{c}{ Number of articles } & TC & ACPA \\
\cline { 2 - 4 } & $\mathbf{2 0 0 5 - 0 9}$ & $\mathbf{2 0 1 0 - 1 4}$ & $\mathbf{2 0 0 5 - 1 4}$ & & \\
\hline USA & 40 & 131 & 171 & 3150 & 18.42 \\
China & 6 & 152 & 158 & 1204 & 9.19 \\
Canada & 21 & 57 & 78 & 1885 & 24.17 \\
UK & 21 & 54 & 75 & 2641 & 35.21 \\
France & 12 & 48 & 60 & 1173 & 19.55 \\
India & 2 & 41 & 43 & 245 & 5.7 \\
Germany & 5 & 31 & 36 & 510 & 14.17 \\
Italy & 5 & 30 & 35 & 553 & 15.8 \\
Australia & 5 & 29 & 34 & 518 & 15.23 \\
The Netherlands & 4 & 27 & 31 & 364 & 11.74 \\
World & & 577 & 1096 & & \\
\hline ACPA Average & 5 & & & 34 &
\end{tabular}

$\mathrm{ACPA}=$ Average citations per article, $\mathrm{TC}=$ Total citations 
For example, DNA barcoding technology inventors and International Barcode of Life (iBOL), the largest biodiversity genomics initiative, which created the digital identification systems for biodiversity is also at Canada. However, developed countries such as China, India, and Brazil are showing a rapid increase in their publication share as well. One of the reasons is that BOL has established a central node in China and a regional node in India for Asia Pacific countries. It is possible that these nodes of $\mathrm{iBOL}$ may have had an effect on the number of publications from these countries

\section{Publications Performance of Selected Institutions}

The performance of different institutions was evaluated on the basis of the affiliation of at least one author with these institutions. Table 5 represents the publication output of the top 20 most productive institutions in genomic research, along with their output, citation received and h-index value. Among the top 20 most productive institutions in genomic research, eight institutions are from USA, five from Canada, two each from Germany and China, one each from Denmark, France, and Brazil. These 20 institutions account for $41.68 \%$ share ( 888 articles) of the publications output in the world, with an average output of $44.35 \%$ per institution. Among these, four institutions have registered higher publications share than the group average. The most productive institution is the University of Guelph,
Canada (216) with the highest h-index of 44, followed by the Natural History Museum, UK (75) National Museum of Natural History, USA (61) followed by others [Table 5].

In the average citation per article registered by the total articles of these 20 institutions, genomics research is at 26.43. In this, nine institutions have registered comparative higher impact than the group average. The highest impact of 51.7 citations per article was scored by the University of California, followed by National Museum of Natural History, USA (44.21), University of Guelph, Canada, followed by others. Comparing the performance of these institutions on the basis of h-index, seven institutions achieved a higher h-index value than the group average of 13.85 [Table 5]. Interestingly, University of California ranked $14^{\text {th }}$ in the number of article publications but ranked first in order of the average citation per article, with the h-index score more than the group average. The University of Toronto occupies the $10^{\text {th }}$ rank in terms of the number of articles published but ranked $5^{\text {th }}$ in terms of average citations per article and h-index, respectively.

Table 6 displays the publication share of top 10 institutions in ethnobotany genomics research for the period 20052014. Comparing the potential of these institutions on the basis of publication output, two institutions have published higher number of articles than the group average of 25.8 . Interesting, among the top 10 institutions, five were from

Table 5: The top 20 productive institutions of genomics research

\begin{tabular}{|c|c|c|c|c|}
\hline Name & TA & TC & ACPA & h-index \\
\hline University of Guelph, Canada & 216 & 9382 & 43.43 & 44 \\
\hline The Natural History Museum, UK & 75 & 1645 & 21.9 & 20 \\
\hline National Museum of Natural History, USA & 61 & 2697 & 44.21 & 17 \\
\hline The National Museum of Natural History, France & 56 & 797 & 14.23 & 15 \\
\hline Chinese Academy of Medical Sciences, China & 48 & 575 & 11.97 & 11 \\
\hline The University of British Columbia, Canada & 39 & 1086 & 27.84 & 12 \\
\hline Imperial College London, UK & 36 & 1556 & 43.22 & 17 \\
\hline Agriculture and Agri-Food, Canada & 35 & 871 & 24.88 & 13 \\
\hline American Museum of Natural History, USA & 32 & 889 & 27.87 & 13 \\
\hline University of Toronto, USA & 31 & 1213 & 39.12 & 15 \\
\hline University of Florida, USA & 29 & 1185 & 40.85 & 13 \\
\hline University of New Brunswick, Canada & 28 & 721 & 25.75 & 12 \\
\hline Ludwig Maximilian University of Munich, Germany & 28 & 366 & 13.07 & 9 \\
\hline University of California, USA & 27 & 1396 & 51.70 & 14 \\
\hline Harvard University, USA & 26 & 288 & 11.07 & 9 \\
\hline Chinese Academy of Sciences, China & 26 & 198 & 7.61 & 6 \\
\hline Brausxhweig University of technology, Germany & 25 & 813 & 32.52 & 12 \\
\hline University of Copenhagen, Denmark & 24 & 463 & 19.29 & 8 \\
\hline Royal Ontario Museum, Canada & 23 & 523 & 22.73 & 11 \\
\hline University City of Sao Paulo, Brazil & 23 & 126 & 5.47 & 6 \\
\hline
\end{tabular}

$\mathrm{TA}=$ Total articles, $\mathrm{TC}=$ Total citations, $\mathrm{ACPP}=$ Average citations per article 
Table 6: The top 10 productive institutions of ethnobotany genomics

\begin{tabular}{lcccc}
\hline Name & TA & TC & ACPA & h-Index \\
\hline Chinese Academy of Medical Sciences, China & 71 & 4152 & 58.47 & 36.34 \\
University of Guelph, Canada & 42 & 1526 & 15 & 16 \\
Chinese Academy of Sciences, China & 24 & 360 & 2.21 & 58.18 \\
China Academy of Chinese Medical Sciences, China & 23 & 51 & 37.76 & 11.87 \\
National Museum of Natural History, USA & 22 & 1280 & 76.14 & 11 \\
University Joseph Fourier, France & 17 & 178 & 73.47 \\
Kunming Institute of Botany, China & 15 & 1142 & 11 \\
Royal Botanic Garden Edinburgh, UK & 15 & 1102 & 36.92 \\
The Natural History Museum, UK & 15 & 517 & 7 \\
Hubei University, China & 14 & & 7 \\
\hline
\end{tabular}

$\mathrm{TA}=$ Total articles, $\mathrm{TC}=$ Total citations, $\mathrm{ACPP}=$ Average citations per article

China. Further, bearing in mind, the quality of articles, the top productive institutions have received a total of 10950 citations for 258 articles, with an average citation per article of 42. Four institutions have listed higher impact than the average. Assessing the performance of these institutions on the basis of the h-index, five institutions have achieved a higher h-index value than the group average of 10.3.

Calculating the performance of these institutions, output, citation received and $\mathrm{h}$-index, the most productive institutions include Chinese Academy of Medical Sciences (China), University of Guelph (Canada), National Museum of Natural History (USA), and Royal Botanic Garden Edinburgh (UK). There can be several factors that could have influenced the quality and quantity of the publications of these institutions. One factor is that in the recent years, these institutions have initiated the establishing of consortiums and projects in collaboration with other countries and institutions. For example, Barcode of Life Database, iBOL and Canadian Center for DNA Barcoding are located at the University of Guelph (Canada). The Consortium for the Barcode of Life is also hosted by the National Museum of Natural History (USA), and Plant Working Group of the Consortium for the Barcode of Life is chaired by the Royal Botanic Garden Edinburgh, (UK).

In recent years, research in ethnobotany genomics has been growing rapidly. In August 2009, the Barcoding Chinese Plants Project and a Large-Scale Scientific Facility, was initiated with the support from the Chinese Academy of Sciences. China has developed Medicinal Materials DNA Barcode Database (MMDBD) for recording the DNA barcode sequences, basic information and the key references of medicinal materials. MMDBD contains over 1600 species of medicinal materials listed in the Chinese Pharmacopoeia and American Herbal Pharmacopoeia (http://137.189.42.34/mherbsdb/).

\section{Publication Output of Select Authors}

In the publication output, twenty authors have been identified as productive authors who have contributed 472 articles, with an average of 23.6 articles per author and have accounted for $22.18 \%$ of the genomics research publications output in the world during 2003-2013. Six authors have published a higher number of articles than the group average (22.18). They are PD Hebert with 88, followed by R Hanner (40) J Song (31) M Hajibabaei (27) H Yao (25) and D Steinke (24) articles. Considering the quality and the impact of the articles, these authors have received a total of 22597 citations for 472 articles, with an average of 43.342 citations per article. Of this, six authors have registered a higher impact than the average. They are DH Janzen with average citations of 144.05 per article followed by W Hallwachs (129.66) PDN Hebert (82.58), M Hajibabaei (79.66), MA Smith (55. 37), RD Ward (55.22), and NV Ivanova (52.06). Furthermore, judging the output of these authors on the basis of h-index, five authors have achieved a higher h-index value than the group average of 11 [Table 7].

The relationship between h-index and the rank order of the 20 most productive authors revealed similar trends. However, it was not the same regarding total citation and the average citation per article. For instance, DH Janzen and W Hallwachs (University of Pennsylvania, USA) ranked $10^{\text {th }}$ and $20^{\text {th }}$, respectively, in the number of article publications, but ranked $1^{\text {st }}$ and $2^{\text {nd }}$ respectively in the average citation per article.

Table 8 shows the most productive authors in ethnobotany genomics research, who have contributed 261 articles with an average of 23.7 articles per author during 2005-2014. Three authors have published higher number of articles than the group average (23.7). The publication impacts of the authors have received a total of 7834 citations for 261 articles, with an 
Table 7: Top 20 Authors in genomics research

\begin{tabular}{|c|c|c|c|c|c|}
\hline Name & Address & TA & TC & ACPA & h-index \\
\hline PDN Hebert & University of Guelph, Canada & 88 & 7266 & 82.5 & 35 \\
\hline RH Hanner & University of Guelph, Canada & 40 & 796 & 19.9 & 12 \\
\hline J Song & Peking Union Medical College Hospital, China & 31 & 527 & 17 & 11 \\
\hline M Hajibabaei & University of Guelph, Canada & 27 & 2151 & 79.66 & 15 \\
\hline H Yao & Chinese Academic of Medical science, China & 25 & 474 & 18.96 & 9 \\
\hline D Steinke & University of Guelph, Canada & 24 & 391 & 16.29 & 10 \\
\hline M Vences & Brausxhweig University of Technology, Germany & 22 & 839 & 38.13 & 10 \\
\hline P Taberlet & The National Centre for scientific Research, France & 19 & 637 & 19.31 & 13 \\
\hline RD Ward & CSIRO Marine and Atmosphere Research, Australia & 18 & 994 & 55.22 & 10 \\
\hline DH Janzen & University of Pennsylvania, USA & 18 & 2593 & 144.05 & 10 \\
\hline GW Saunders & University of New Brunswick Fredericton, Canada & 17 & 530 & 31.17 & 11 \\
\hline E Coissac & Joseph Fourier University, France & 17 & 575 & 33.82 & 12 \\
\hline S Chen & Peking Union Medical College Hospital, China & 17 & 221 & 13 & 7 \\
\hline R Rougerie & University of Guelph, Canada & 16 & 259 & 16.18 & 9 \\
\hline MA Smith & University of Guelph, Canada & 16 & 886 & 55.37 & 9 \\
\hline C Cruaud & Commissioner to the Atomic Energy and Alternative Energies Commission, France & 16 & 183 & 11.43 & 6 \\
\hline NV Ivanova & University of Guelph, Canada & 16 & 833 & 52.06 & 11 \\
\hline M Casiraghi & University of Milan, Italy & 15 & 158 & 10.53 & 6 \\
\hline M Balke & Ludwig Maximillian University, Germany & 15 & 339 & 22.6 & 6 \\
\hline W Hallwachs & University of Pennsylvania, USA & 15 & 1945 & 129.66 & 8 \\
\hline
\end{tabular}

$\mathrm{TA}=$ Total articles, $\mathrm{TC}=$ Total citations, $\mathrm{ACPA}=$ Average citations per article

Table 8: Top 11 Authors in ethnobotany genomics

\begin{tabular}{|c|c|c|c|c|c|}
\hline Name & Address & TA & TC & ACPA & $\mathrm{h}$ index \\
\hline S Chen & Peking Union Medical College Hospital, China & 53 & 1011 & 19.1 & 15 \\
\hline J Song & Peking Union Medical College Hospital, China & 44 & 882 & 20.1 & 13 \\
\hline H Yao & Chinese Academic of Medical science, China & 36 & 180 & 5 & 12 \\
\hline X Pang & Chinese Academy of Medical Sciences, China & 22 & 631 & 28.7 & 9 \\
\hline SG Newmaster & University of Guelph, Canada & 20 & 1194 & 59.7 & 11 \\
\hline P Taberlet & National Centre for scientific Research, France & 16 & 631 & 39.5 & 11 \\
\hline K Luo & Xinjiang Medical University, China & 16 & 473 & 29.6 & 7 \\
\hline WJ Kress & National Museum of Natural History USA & 15 & 1048 & 69.9 & 9 \\
\hline E Coissac & Joseph Fourier University, France & 14 & 636 & 45.5 & 12 \\
\hline DL Erickson & National Museum of Natural History USA & 13 & 870 & 66.9 & 8 \\
\hline PDN Hebert & University of Guelph, Canada & 12 & 278 & 23.2 & 8 \\
\hline
\end{tabular}

$\mathrm{TA}=$ Total articles, $\mathrm{TC}=$ Total citations, $\mathrm{ACPA}=$ Average citations per article

average citation per article of 30 . Five authors have registered higher impact than the average. Examining the performance of these authors on the basis of h-index, six authors have achieved a higher h-index value than the group average of 10.45 . These are S Chen (15) followed by J Song (13) H Yao and Coissac (12 each), GN Newmaster and P Taberlet (11 each).

\section{Subject-wise Break-up of Publication Output}

The world publication output in the field of genomics research during the last 10 years has covered a total of 24 subject areas, as reflected in database classification based on journal subject content. The highest publication output was from Agricultural and Biological Sciences (1481 articles and $38.8 \%$ publication share), followed by Biochemistry, Genetic and Molecular Biology (1070 articles and 28\% publication share), Medicine (499 articles and 13\% publication share), Environmental Science (184 articles and 4.8 publication share) and Immunology and Microbiology (183 articles and 4.7\% publication share), as represented in Table 9.

In Agricultural and Biological Sciences, the number of articles increased from 118 in 2003-2007 to 1158 in 2003-2012, followed by Biochemistry, Genetic and Molecular Biology with an increase from 26 in 2003-2007 to 855 articles in 
2008-2012 [Table 9]. Each of other two subjects also holds a sustainable growth trend. Calculating the performance on the basis of h-index, these two subject categories, Agricultural and Biological Sciences (66) and Biochemistry, Genetic and Molecular Biology (61) have achieved a higher h-index value than the group average of 42.4. However, publication output in the subject categories of Medicine have increased from 13 in 2003-2007 to 403 in recent years (2008-2012) indicating that the medicinal value of biodiversity may continue to be the growing field in the future study of genomics. This may be partly explained by the fact that genomics is the technology for identification of biodiversity.

According to the Scopus database, the ethnobotany genomics researchers are publishing in 23 different subject areas. In terms of publication output, Agricultural and Biological Sciences and Biochemistry, Genetic and Molecular Biology are dominating subjects, and the emerging subject areas include Medicine and Pharmacology, Toxicology and Pharmaceutics which are predominantly concerned with medicinal properties of plants. The cumulative publication share of these four most productive subject areas showed a dramatic increase in the world publication output of $13.61 \%$ during 2005-2009, to 86.38\% during 2010-2014 [Table 10]. The average h-index of these subject areas is 18.75 .

Table 11 shows the nine top most productive journals in terms of the total article in ethnobotany genomic research. The nine most productive journals publishing world research articles together, contributed 253 in ethnobotany genomics, which accounts for $35.63 \%$ of the total output of the world during 2005-2014. Plos One ranked first with $235(31.3 \%)$ published articles followed by Molecular Ecology Resources with 95, and the following eight journals had a total number of articles ranging from 51 to 11 articles [Table 11]. Based on the nine top most productive journals published, Taxon published the smallest number of articles (11) but is ranked first in terms of average citation per article (40). Molecular Ecology Resources ranked ${ }^{1 \text { st }}$ with 7.43 impact factor followed by Molecular Ecology (6.25) and Methods in Molecular Biology (5.92). On analyzing the quality

Table 9: Genomics research output in context of subject areas

\begin{tabular}{|c|c|c|c|c|c|}
\hline \multirow[t]{2}{*}{ Subject categories } & \multicolumn{3}{|c|}{ Number of article } & \multirow[t]{2}{*}{ TC } & \multirow[t]{2}{*}{ h-index } \\
\hline & 2003-07 & 2008-12 & 2003-13 & & \\
\hline Agricultural and Biological Sciences & 118 & 1158 & 1481 & 22,427 & 66 \\
\hline Biochemistry, Genetic and Molecular Biology & 26 & 855 & 1070 & 19,502 & 61 \\
\hline Medicine & 13 & 403 & 499 & 4931 & 33 \\
\hline Environmental science & 32 & 119 & 184 & 3556 & 28 \\
\hline Immunology and Microbiology & 8 & 138 & 182 & 1998 & 24 \\
\hline
\end{tabular}

$\mathrm{TC}=$ Total citations

Table 10: Ethnobotany genomics research output in context of subject areas

\begin{tabular}{|c|c|c|c|c|c|}
\hline \multirow[t]{2}{*}{ Subject categories } & \multicolumn{3}{|c|}{ Number of articles } & \multirow[t]{2}{*}{ TC } & \multirow[t]{2}{*}{ h-index } \\
\hline & 2005-09 & 2010-14 & 2005-14 & & \\
\hline Agricultural and Biological Sciences & 80 & 393 & 473 & 2553 & 20 \\
\hline Biochemistry, Genetic and Molecular Biology & 51 & 306 & 357 & 617 & 20 \\
\hline Medicine & 16 & 189 & 205 & 1533 & 20 \\
\hline Pharmacology, Toxicology and Pharmaceutics & 7 & 90 & 97 & 608 & 15 \\
\hline
\end{tabular}

$\mathrm{TC}=$ Total citations

Table 11: Preferred journals of ethnobotany genomic research

\begin{tabular}{lcccc}
\hline Journal & TA & TC & ACPA & Impact factor (2012) \\
\hline Plos One & 95 & 1320 & 13.89 & 3.73 \\
Molecular Ecology Resources & 51 & 1063 & 20.84 & 7.43 \\
China Journal of Chinese material medical & 22 & 6 & 0.27 & $\mathrm{NA}$ \\
Molecular Ecology & 19 & 261 & 13.73 & 6.27 \\
Journal of Systematics and Evolution & 16 & 194 & 12.12 & 1.64 \\
Methods in Molecular Biology & 16 & 47 & 2.93 & 5.92 \\
American Journal of Botany & 12 & 205 & 17.08 & 2.58 \\
Taxon & 11 & 442 & 40.18 & 2.782 \\
Planta Medica & 11 & 302 & 27.45 & 2.35 \\
\hline
\end{tabular}

$\mathrm{TA}=$ Total articles, $\mathrm{TC}=$ Total citations, $\mathrm{ACPA}=$ Average citations per article, NA $=$ Not available 
and citation impact of ethnobotany genomics of these journals, it is found that the average citation per article is 16.49 , with impact factor of these journals ranging between 2 and 7 [Table 12].

\section{International Collaboration Publications Output in Select Countries}

Looking at the overall trend of the major international collaborative partners of the world in genomics research, as reflected in its international co-authored papers, 85 countries have published two or more collaborative articles during 2003-2013. USA is the major collaborating country during the period 2003-2013 with a contribution of 780, followed by UK (567), Canada (515), France, Germany, Australia, Italy, and Spain (with a share of publications between 200 and 400), and China, The Netherlands, Sweden, and Japan (with a share of publications between 120 and 187).

Table 12: Ethnobotany genomics research publications with foreign collaboration

\begin{tabular}{lcccl}
\hline Countries & 2005-09 & $\mathbf{2 0 1 0 - 1 4}$ & $\mathbf{2 0 0 5 - 1 4}$ & $\begin{array}{l}\text { Major } \\
\text { collaborator } \\
\text { country }\end{array}$ \\
\hline USA & 53 & 136 & 189 & Canada \\
UK & 33 & 118 & 151 & USA \\
France & 45 & 74 & 119 & USA \\
Canada & 27 & 58 & 85 & USA \\
Germany & 13 & 59 & 72 & UK \\
China & 5 & 55 & 60 & USA \\
The Netherlands & 4 & 53 & 57 & UK \\
Italy & 5 & 39 & 44 & France \\
Australia & 5 & 35 & 40 & UK \\
India & 1 & 21 & 22 & Canada \\
\hline
\end{tabular}

Analyzing the shift in international collaborative publications share of the major collaborative partner countries of the world, between the two periods of 20032008 and 2009-2013, it was found that the publication share of all collaborating partner countries have increased. USA ranks the highest (from 79 to 701), followed by UK (from 38 to 529), Canada (from 57 to 458), France and Germany (between 398 and 388), Australia, Italy and Spain (from 267 to 200), China, Netherlands, Sweden and Japan (from 187 to 120). Among them, Italy, China and Japan have registered a rapid growth from 5, 4 and 6-196, 183 and 114, respectively, during 2002-2008 and 2009-2013 [Figure 2].

In terms of BRICS countries, international collaborative article share of China was 187, Brazil with 145, Russia with 85, India with 39 and South Africa 22 during 2003-2013. There was an increase in the shift pattern from 4 to 183 in China, from 4 to 141 in Brazil, 6-79 in Russia, in India 1-38, and from 1 to 21 in South Africa, respectively, from 2003-2008 to 2009-2011 [Figure 3]. Figure 4 represents the distribution of the number of Indian publications involving collaboration with foreign partners. Canada and USA are the major collaborators with a contribution of six each, followed by Germany at five, and China, Italy, Malaysia, and Spain with two each. The total number of these publications amounts to 39, which accounts for $40 \%$ of total publications. In this, various institutes have collaborative projects with foreign counterparts as well.

For ethnobotany genomic research, the international collaborative publication of 10 institutions is 839

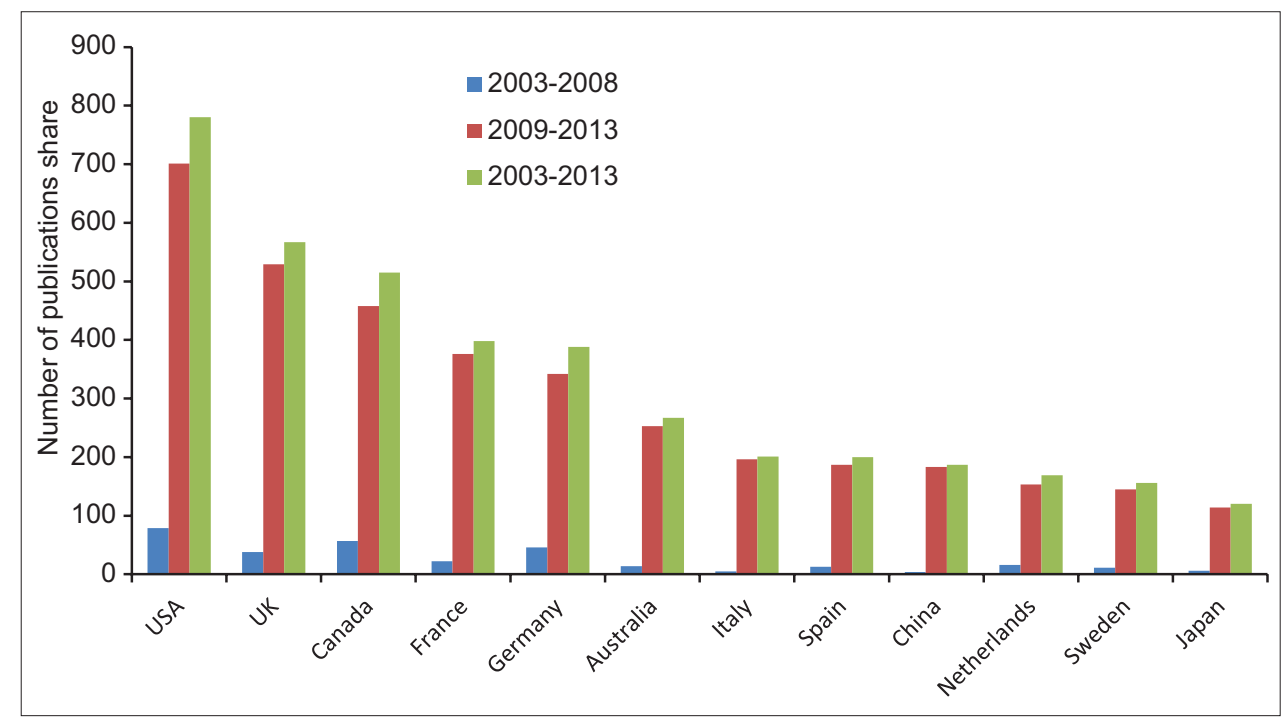

Figure 2: Major genomic research publications with foreign collaboration 


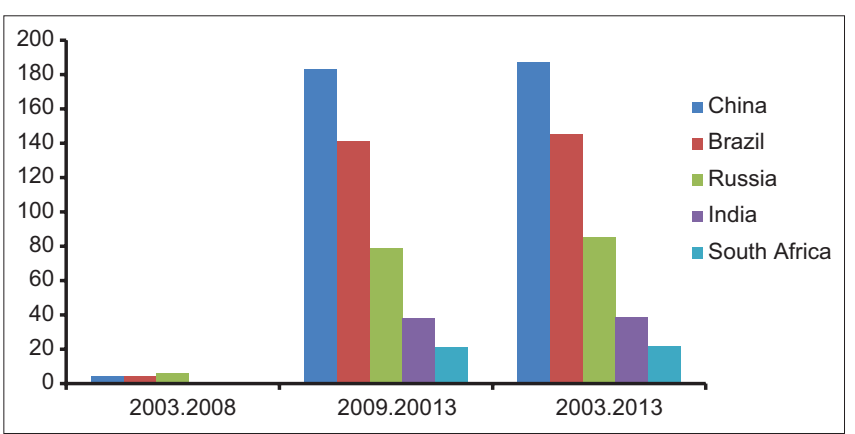

Figure 3: The collaboration trends of the Brazil, Russia, India, China, and South Africa countries in genomics research

with an average share of international collaborative publications at 83.9 [Table 12]. Four institutions have published higher share of international collaborative publications than the average share of international collaborative publications of all 10 institutions. While comparing the foreign collaboration of countries, a majority of the collaborations increased after 2010. The highest collaboration among the top is USA, followed by UK. The maximum share (189) of foreign collaborative publications are by USA, followed by UK (151), France (119), Canada (85) and Germany, China, Netherland, Italy, Australia, India (ranging from 72 to 22), as represented in Table 12 and there was an increase in the shift pattern from 5 to 55 in China, from 1 to 21 in India respectively from 2005-2009 to 2010-2014.

\section{FINDINGS AND CONCLUDING REMARKS}

The current study is the first detailed scientometric analysis of the number of publications in genomics and ethnobotany genomics research. A noticeable increase of interest in this research is evident worldwide, as reflected by the continuously increasing number of publications since the introducing of the DNA barcoding in 2003. As a result, more countries, institutions, and authors are engaged in this research. Their involvement in this subject area, number of published items (index of productivity), number of citations and the h-index (index of quality), were determined and analyzed in this study. According to this study, USA is ranked top in publication of articles, followed by Canada and the UK. Interestingly, of all the institutions and authors participating in ethnobotany genomics research, the University of Guelph (Canada), and P.D.N. Hebert, founder of DNA barcoding technology, recorded the highest number of publications. Moreover, data analysis showed that the University of

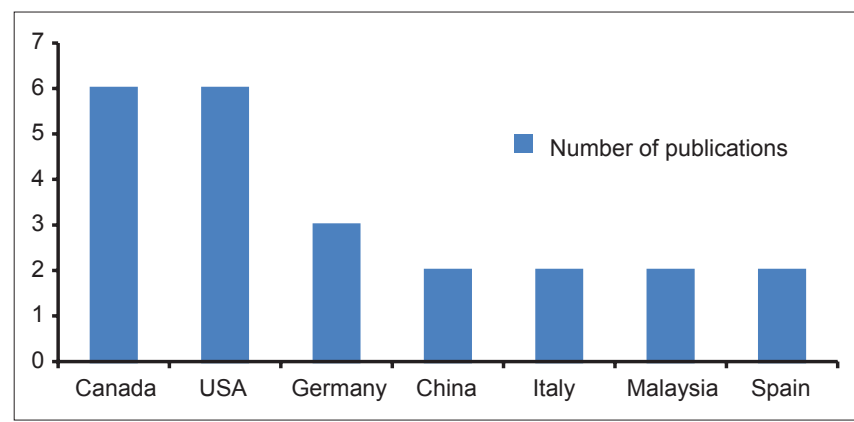

Figure 4: India's genomics research publications with foreign collaboration

Guelph and PD Hebert have the highest total citation and h-index of published articles. Looking at the overall trend of international collaborative partners, USA, $\mathrm{UK}$, and Canada are the major collaborating countries. Agricultural and Biological Sciences, Biochemistry and Genetic and Molecular Biology, by virtue of being the flagship subject areas of the field, published the most number of articles

The findings of the year wise distribution of China and India on ethnobotany genomics brings out the fact that there is rapid growth in terms of publication outputs from 2005-2009 to 2010-2014. In China, a large number of research institutions and authors have contributed to the ethnobotany genomics research. The above findings clearly indicate that China and India have positions in the rankings in ethnobotany genomics research, whereas in the field of genomics research, western countries (USA, Canada, and UK) dominate the top position. This contradiction can be best explained from the fact that both China and India had a very old history and tradition of advanced development in the field of medicine. Ayurvedic medicines in India are one such tradition which is still in existence. However, in the case of genomics research, the domination of the western countries can be explained in two factors. First, advancement in genomics research is directly proportional to the level of advancement in modern science and technology, and the resources (manpower, finance, etc.). Second, effective networking and public policy in the area of genomics research among the western countries, and also their ability to penetrate in other developing countries in research places them in a very advantageous position.

The present study indicates that scientists are now recognizing the need to describe and document the 
wide-ranging biodiversity that remains to be explored, and acknowledge the importance of ethnobotany genomics as a valuable technology, that can help expedite the discovery and description of new species. The failure to respond to the bigger problems posed by the $21^{\text {st }}$ century such as widespread extinction of species and the capital incentives in other fields of research, has made scientists more inclined toward a research career in molecular biology for instance, rather than traditional taxonomy. However as a result of this advancement, research relating to ethnobotany genomics may bring about a change in the situation, and fill the shortfall in the number of taxonomists. Current ethnobotany genomics research proposals seek to involve not only developed countries with established scientific infrastructure and expertise, but also encourage poorer and developing countries to establish ethnobotany genomics programs for their biodiversity. There are many organizations and projects related to ethnobotany genomics of species in the world. For example in 2010, the iBOL, with the cooperation of 26 countries, was launched to establish an automated identification system based on a DNA barcode library covering all biodiversity. iBOL has launched many global campaigns to build DNA barcode libraries of fishes barcode of life initiative, all birds barcoding initiative, mammals mammalia barcode of life, marine barcode of life, polar barcode of life, Human health, and insect groups etc.

Ethnobotany genomics development may have power for clarifying the identities and limits of species, uncovering new and often unknown species, and allowing identification of difficult specimens. As can be observed from the study of ethnobotany genomics research across the globe, India's performance is far from what it can achieve. The social diversities and richness in various indigenous and communities and their relationship with the biodiversity can give a huge impetus in ethnobotany genomics research in India. The North East India in terms of geographical size is only $8 \%$ of India's geographical area. However, this area is very rich in cultural heritage and biodiversity. In addition, communities in this region also possess traditional knowledge relating to medicinal values of the biodiversity around them. In this context, it seems that the scope of expanding research in ethnobotany genomics is immense in India.

\section{REFERENCES}

1. Bannister K, Barrets K. Challenging the status quo in ethnobotany: A new paradigm for publication may protect cultural knowledge and traditional resources. Cult Surv Q 2001; 24:10 3.

2. Cotton CM. Ethnobotany: Principles and Applications. Chichester, England John Wiley and Sons; 1996.

3. Balick MJ, Cox PA. Plants, People, and Culture: The Science of Ethnobotany. New York: Scientific American; 1996.

4. Sheng Ji P. Ethnobotanical approaches of traditional medicine studies: Some experiences from Asia. Pharm Biol 2001; 39 Suppl 1:74 9.

5. Wagner H, Bauer R, Melchart D, Xiao PG, Staudinger A. Chromatographic Fingerprint Analysis of Herbal Medicines: Thin layer and High Performance Liquid Chromatography of Chinese Drugs. $2^{\text {nd }}$ ed., Vol. I, II, Wien: Springer; 2011.

6. Kaplan J, Chavan P, Warude D, Patwardhan B. Molecular markers in herbal drug technology. Curr Sci 2004; 87:159 65.

7. Pereira F, Carneiro J, Amorim A. Identification of species with DNA based technology: Current progress and challenges. Recent Pat DNA Gene Seq 2008; 2:187 99.

8. Hebert PD, Cywinska A, Ball SL, deWaard JR. Biological identifications through DNA barcodes. Proc Biol Sci 2003; 270:313 21.

9. Becker S, Hanner R, Steinke D. Five years of FISH BOL: Brief status report. Mitochondrial DNA 2011;22 Suppl 1:3 9.

10. Armstrong KF, Ball SL. DNA barcodes for biosecurity: Invasive species identification. Philos Trans R Soc Lond B Biol Sci 2005; 360:1813-23.

11. Ball SL, Armstrong KF. DNA barcodes for insect pest identification: A test case with tussock moths (Lepidoptera: Lymantriidae). Canadian Journal of Forest Research 2006; 36:337-350.

12. Frézal $L$, and Raphael L. Four years of DNA barcoding: current advances and prospects. Infection, Genetics and Evolution 2008; 8(5):727-736.

13. Ragupathy S, Newmaster SG, Murugesan M, Balasubramaniam V. DNA barcoding discriminates a new cryptic grass species revealed in an ethnobotany study by the hill tribes of the Western Ghats in southern India. Mol Ecol Resour 2009; 9 Suppl s1:164 71.

14. Newmaster SG, Ragupathy S. Ethnobotany genomics-Discovery and innovation in a new era of exploratory research. J Ethnobiol Ethnomed 2010; 6:2.

15. Ronsted N, Savolainen V, Molgaard P, Jager AK. Phylogenetic selection of Narcissus species fordrugdiscovery. Biochem Syst Ecol 2008; 36:417 22.

16. Ronsted N, Symonds MRE, BirkholmT, Christensen SB, Meerow AW, Molander M, et al. Can phylogeny predict chemical diversity and potential medicinal activity in plants? A case study of amaryllidaceae. BMC. Evolutionary Biology 2012; 12:182.

17. Saslis Lagoudakis $\mathrm{CH}$, Klitgaard, BB, Forest F, Francis L, Savolainen V, et al. The use of phylogeny to interpret cross cultural patterns in plant use and guide medicinal plant discovery: An example from Pterocarpus (Leguminosae). PLoS One 2011;6:e22275.

18. Maloles JR, Berg K, Ragupathy S, Nirmala BC, Althaf KA, Palanisamy VC, et al. The fine scale ethnotaxa classification of millets in southern India. J Ethnobiol 2011; 31:262 8.

How to cite this article: Varah F, Desai PN. Ethnobotany genomics research: Status and future prospects. J Sci Res 2015;4:29-39.

Source of Support: Nil, Conflict of Interest: None declared 